\title{
British Isles survey of multiple sclerosis in twins: MRI
}

\author{
J W Thorpe, C J Mumford, D A S Compston, B E Kendall, D G MacManus, \\ W I McDonald, D H Miller
}

\begin{abstract}
64/105 subjects who have a twin with multiple sclerosis included in a study of clinical concordance also underwent MRI of the brain. 8/23 monozygotic and 1/41 dizygotic co-twins from this subgroup were clinically concordant of whom $8 / 9$ had MRI appearances typical of multiple sclerosis. Of the 48 clinically discordant twins aged less than 60, abnormalities on MRI were detected in $6 / 15$ (40\%) monozygotic and $13 / 33(39 \%)$ dizygotic twins compared with $7 / 37$ (19\%) healthy agematched controls. Abnormalities on MRI typical of multiple sclerosis (defined by the Fazekas criteria) were, however, present in only $2 / 15(13 \%)$ monozygotic and $3 / 33$ (9\%) dizygotic twins and $0 / 37$ controls. These results suggest that about $10 \%$ of monozygotic and dizygotic twins have "subclinical multiple sclerosis". It is likely that most of the MRI abnormalities seen in clinically discordant twins, however, represent incidental pathology.
\end{abstract}

$(\Im$ Neurol Neurosurg Psychiatry 1994;57:491-496)

For a given disease, the determination of concordance rates in twins permits an estimation of the aetiological contribution made by genetic factors. ${ }^{1}$ Higher concordance rates in monozygotic than dizygotic twins indicate a genetic contribution, but if the monozygotic concordance rate is less than $100 \%$, genetic factors alone, or at least those determined by the germ cell line, are not of themselves sufficient to cause the disease.

Several large studies of clinical concordance for multiple sclerosis in twins have been published..$^{2-12}$ Despite considerable methodological differences, a consistent pattern has emerged; most but not all studies have identified a higher concordance rate in monozygotic twins, and all are in accord that the monozygotic concordance rate falls well short of $100 \%$. Two of the largest population based surveys ${ }^{211}$ produced remarkably similar results (25\% monozygotic and $2-3 \%$ dizygotic concordance) although the recent French study ${ }^{12}$ found low concordance rates that were independent of zygosity.

It might be concluded from the current twin data that although genetic factors make an important contribution to the aetiology of multiple sclerosis, additional environmental factors are probably needed to produce the disease. An important question in multiple sclerosis twin studies is the reliability of concordance rates that have been determined by an assessment of clinical features alone. The certainty of clinical diagnosis varies especially in the early stages, and this is reflected in the use of criteria that allow for definite, probable, and possible categories. Furthermore, and potentially of much greater importance, the disease may run an extremely benign course ${ }^{13-15}$ and indeed may first be discovered only at necropsy. ${ }^{16-21}$ One postmortem series ${ }^{19}$ identified multiple sclerosis that had not been suspected in life with a frequency of 1 in 500, which suggests that completely asymptomatic disease may be as common as the clinically expressed form. Additional suggestive evidence for clinically silent multiple sclerosis during life comes from the finding of CSF oligoclonal bands in clinically unaffected twins ${ }^{22}$ and abnormalities of evoked potentials in healthy siblings of patients with multiple sclerosis, especially those who are identical at the HLA-A and HLA-B loci. ${ }^{23}$ Taken together, the evidence suggests that clinical ascertainment alone fails to detect an appreciable number of cases who actually have multiple sclerosis.

MRI now provides a sensitive means for detecting, in vivo, the characteristic cerebral lesions of multiple sclerosis. ${ }^{24}{ }^{25}$ White matter lesions, most of which are asymptomatic, are seen in well over $90 \%$ of patients with clinically definite multiple sclerosis. ${ }^{26}$ Furthermore, multiple asymptomatic white matter lesions are already visible in $50 \%-70 \%$ of patients at presentation with a first episode of suspected demyelination ${ }^{27-31}$ and have also recently been reported in healthy first degree relatives of patients with multiple sclerosis. ${ }^{32} 33$ MRI should therefore be of value in a multiple sclerosis twin study by detecting subclinical disease in clinically normal twins, leading to a more reliable estimate of concordance than that obtained from clinical criteria. It would also be useful in clarifying the diagnosis in clinically possible cases. A major limitation to using MRI to detect multiple sclerosis in asymptomatic subjects, however, is that the abnormalities seen are not specific; there are many causes of multifocal white matter lesions, ${ }^{34-36}$ of which the most frequent is age-related changes, most likely due to small vessel disease. ${ }^{37-41}$ This produces abnormalities of white matter in a large proportion of healthy controls over the age of 60 , and in smaller numbers of younger age groups. ${ }^{42-45}$ To determine the significance of 
abnormalities seen in asymptomatic twins, it is therefore crucial to obtain MRI scans from age matched controls and to use criteria that improve the specificity of abnormalities detected by MRI in multiple sclerosis. We now report the brain MRI findings obtained in 64 co-twins of patients with multiple sclerosis and 40 healthy controls.

\section{Methods \\ TWINS}

The group consisted of 64 of the 105 co-twins interviewed and examined as described elsewhere. ${ }^{2}$ Briefly, recruitment (over a period of 28 months) was predominantly via members of the Association of British Neurologists, who were asked to ascertain of all patients with multiple sclerosis seen by them whether they were a twin. Index cases and co-twins were all assessed by one of us (CJM) who used a standardised questionnaire to obtain clinical details followed by a full neurological examination. All 105 co-twins were requested to attend for MRI: of the 64 who were scanned 23 were monozygotic aged 21-53 (mean 37.5) years (four men) and 41 dizygotic aged 24-67 (mean 44.3) years (22 men). There were 21 monozygotic and 20 dizygotic (31 women) twins who were not scanned.

\section{CONTROLS}

The control group consisted of 40 healthy volunteers aged 18-72 (mean $41 \cdot 3$ ) years (20 men). They were recruited from hospital staff and friends of patients attending the unit. Relatives of patients with multiple sclerosis were excluded. All filled in a general health questionnaire seeking evidence of previous neurological illness, hypertension, cerebrovascular or cardiovascular disease, and diabetes.

MRI

Most twins were imaged at the National Hospitals for Neurology and Neurosurgery (NHNN) on a Picker $0.5 \mathrm{~T}$ (24 subjects) or General Electric 1.5 T Signa system (28), provided by The Multiple Sclerosis Society of Great Britain and Northern Ireland. Smaller numbers were scanned in other centres in the United Kingdom on $0.15 \mathrm{~T}(2), 0.5 \mathrm{~T}$ (4), or $1.5 \mathrm{~T}$ (6) systems.

Moderately T2-weighted 5 or $10 \mathrm{~mm}$ axial images of the brain were obtained in all cases and more proton density-weighted images in some subjects. For example, the imaging

Table 1 MRI findings in clinically concordant twins

\begin{tabular}{|c|c|c|c|c|}
\hline Zygosity & $\begin{array}{l}\text { Age } \\
(y)\end{array}$ & $\begin{array}{l}\text { Clinical } \\
\text { classification }\end{array}$ & $\begin{array}{l}\text { Criteria of } \\
\text { Fazekas } \\
\text { et al }\end{array}$ & Comments \\
\hline $\begin{array}{l}\text { Monozygotic } \\
\text { Monozygotic } \\
\text { Monozygotic } \\
\text { Monozygotic } \\
\text { Monozygotic } \\
\text { Monozygotic } \\
\text { Monozygotic } \\
\text { Monozygotic } \\
\text { Dizygotic }\end{array}$ & $\begin{array}{l}38 \\
43 \\
40 \\
34 \\
47 \\
36 \\
35 \\
21 \\
40\end{array}$ & $\begin{array}{l}\text { Definite } \\
\text { Definite } \\
\text { Definite } \\
\text { Possible } \\
\text { Probable } \\
\text { Definite } \\
\text { Probable } \\
\text { Possible } \\
\text { Definite }\end{array}$ & $\begin{array}{l}\text { Met } \\
\text { Met } \\
\text { Not met } \\
\text { Not met } \\
\text { Not met } \\
\text { Met } \\
\text { Met } \\
\text { Met } \\
\text { Met }\end{array}$ & $\begin{array}{l}\text { Many small lesions } \\
\text { Single lesion only } \\
\text { Many small lesions }\end{array}$ \\
\hline
\end{tabular}

parameters for the Picker $0.5 \mathrm{~T}$ scanner, NHNN, were $S_{2080 / 60}, 5 \mathrm{~mm}$ contiguous slices, field of view $30 \mathrm{~cm}, 2$ excitations, $128 \times 256$ matrix and for the GE Signa $1.5 \mathrm{~T}$ scanner, NHNN, $\mathrm{SE}_{2700 / 32,80}, 5 \mathrm{~mm}$ slices with $2.5 \mathrm{~mm}$ interslice gap, field of view $24 \mathrm{~cm}, 1$ excitation, $192 \times 256$ matrix.

All the controls were imaged on the GE 1.5 T Signa scanner. In $21 \mathrm{~T} 2$ and proton density-weighted axial spin echo were obtained as described but in the remaining 19 fast spin echo images (either $\mathrm{FSE}_{3500 / 19,95}$ or FSE $_{3100 / 76}$ ) were obtained instead.

All images, with controls and twins interdigitated, were interpreted by one of us (BEK) without reference to the clinical history. A scan was judged to be abnormal if there were one or more areas of unequivocal high signal in the brain parenchyma compatible with demyelination. The site and size of every such lesion was noted. Abnormalities on MRI that were obviously not due to demyelination (for example, incidental arachnoid cysts) were ignored. To improve the specificity of MRI for detecting multiple sclerosis, those with an abnormal scan were classified separately according to whether or not they fulfilled the criteria of Fazekas et al. ${ }^{46}$ With this system, MRI diagnosis of multiple sclerosis requires the presence of any two out of three abnormalities: (a) a lesion adjacent to the body of the lateral ventricles; $(b)$ an infratentorial lesion; $(c)$ a lesion greater than or equal to $6 \mathrm{~mm}$ in diameter. Previous evaluation of these criteria in 1500 consecutive patients reported a sensitivity of $81 \%$ and specificity of $96 \%$ for the diagnosis of multiple sclerosis. ${ }^{47}$

\section{Results}

CLINICAL FEATURES

The mean age of the twins scanned was $41 \cdot 8$ (SD 10.4) and of the controls 41.3 (SD 13.2). The mean age of the twins not scanned was 44.2 (SD 12.9). Nine of the twins who were imaged (eight monozygotic and one dizygotic) were classified on clinical criteria alone as having possible, probable, or definite multiple sclerosis (table 1). There were two men and seven women. There were no significant differences in the demographic features of the 64 twins who were and the 41 who were not scanned. The most common reason given for refusal to be scanned was unwillingness to travel.

There were no differences between the 55 clinically unaffected co-twins and controls for frequency of hypertension or other cardiovascular disease, migraine, or cerebrovascular disease and none gave a history of neurological episodes suggestive of demyelination.

MRI FINDINGS

Clinically affected twins

There was good agreement between clinical and MRI findings (table 1). All nine twins had an abnormal scan (fig 1), and six fulfilled the criteria of Fazekas $e t a^{46}$ (four definite, one probable, and one possible multiple sclerosis). 
Figure 1 MRI of 21 year old monozygotic twin with clinically possible multiple sclerosis showing multiple periventricular lesions.

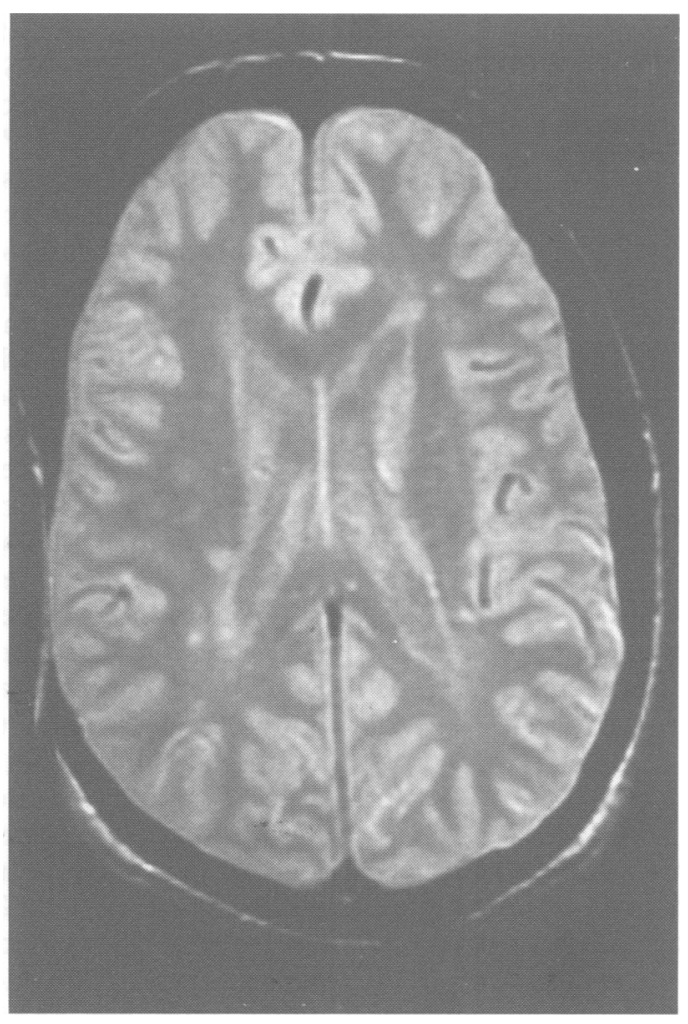

One twin with definite and one with probable multiple sclerosis displayed multiple small $(\leqslant 5 \mathrm{~mm})$ cerebral white matter lesions characteristic of multiple sclerosis, but there were no infratentorial or larger lesions to satisfy the criteria. One twin with clinically possible multiple sclerosis showed a single lesion in the cerebral white matter. Eight of nine therefore had an abnormal scan typical of multiple sclerosis.

In three twins, MRI increased the diagnostic

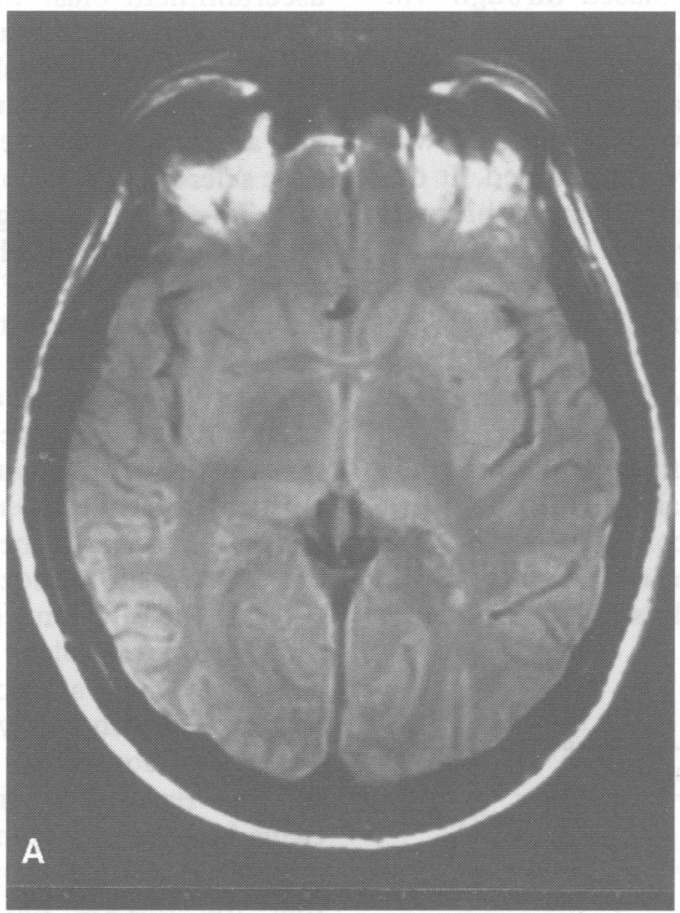

certainty. Multiple white matter lesions were seen in two monozygotic twins, aged 35 and 47 , with probable multiple sclerosis and in a 21-year-old monozygotic twin with possible multiple sclerosis based on clinical criteria alone; using the criteria of Poser et al, ${ }^{48}$ these patients were reclassified as having definite and probable multiple sclerosis respectively after including the MRI result.

\section{Clinically unaffected twins}

MRI was obtained in $\mathbf{5 5}$ asymptomatic twins, 15 monozygotic (aged 30-53, mean 37.9 y), and 40 dizygotic (aged 24-67, mean 44.4). Overall, lesions were detected in $6 / 15(40 \%)$ monozygotic and $20 / 40(50 \%)$ dizygotic twins (fig 2) and in $8 / 40(20 \%)$ controls (table 2). The difference between dizygotic twins and controls was significant $(p<0.01$, Fisher's exact test). This difference was, however, largely due to a group of elderly (age $\geqslant 60$ ) dizygotic twins, all of whom had an abnormal scan. When the analysis was confined to those aged less than 60, MRI showed abnormalities in 6/15 (40\%) monozygotic twins, 13/33 (39\%) dizygotic twins and $7 / 37(19 \%)$ controls, and the difference between dizygotic twins and controls was no longer significant.

All lesions detected in controls were small and none of the control subjects fulfilled the criteria of Fazekas et $a l^{46}$ whereas eight clinically unaffected twins did. Three of these eight were older than 60 . When the analysis was confined to those younger than 60 , the criteria were satisfied in only $2 / 15$ (13\%) monozygotic twins, $3 / 33$ (9\%) dizygotic twins, and $0 / 37$ controls, whereas minor MRI abnormalities not fulfilling the criteria were seen in $4 / 15(27 \%)$ monozygotic twins, $10 / 33$ $(30 \%)$ dizygotic twins, and 7/37 (19\%) controls.

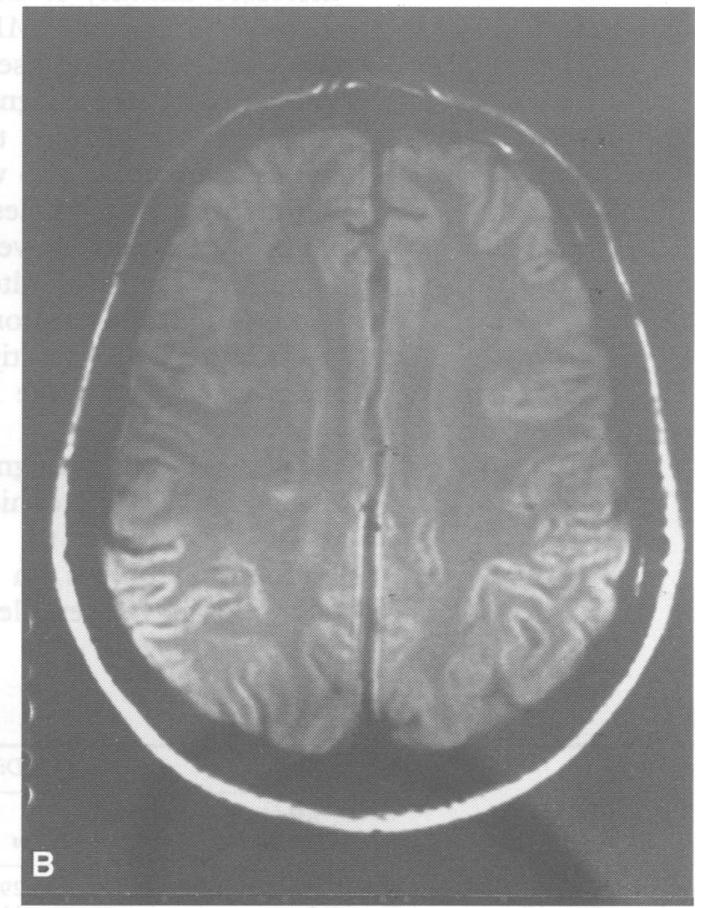

Figure 2 Criteria of Fazekas et al ${ }^{46}$ met in a 41 year old clinically normal dizygotic twin showing two periventricular white matter lesions. The subject also had a brainstem lesion. 
Table 2 MRI findings in clinically discordant twins and controls

\begin{tabular}{|c|c|c|c|c|c|}
\hline $\begin{array}{l}\text { Age } \\
(y)\end{array}$ & Normal MRI & $\underset{(\text { Faz- })}{M R I+}$ & $\begin{array}{l}M R I+ \\
(F a z+)\end{array}$ & Total & $\begin{array}{l}\text { No (\%) } \\
\text { of abnormal } \\
\text { scans }\end{array}$ \\
\hline $\begin{array}{c}\text { Controls: } \\
<60 \\
\geqslant 60 \\
\text { Total }\end{array}$ & $\begin{array}{r}30 \\
2 \\
32\end{array}$ & $\begin{array}{l}7 \\
1 \\
8\end{array}$ & $\begin{array}{l}0 \\
0 \\
0\end{array}$ & $\begin{array}{r}37 \\
3 \\
40\end{array}$ & $\begin{array}{l}7(19) \\
1(33) \\
8(20)^{\star}\end{array}$ \\
\hline $\begin{array}{l}\text { Monozygotic } \\
\quad \text { (all < 60 years) }\end{array}$ & 9 & 4 & 2 & 15 & $6(40)$ \\
\hline $\begin{array}{c}\text { Dizygotic: } \\
<60 \\
\geqslant 60 \\
\text { Total }\end{array}$ & $\begin{array}{r}20 \\
0 \\
20\end{array}$ & $\begin{array}{r}10 \\
4 \\
14\end{array}$ & $\begin{array}{l}3 \\
3 \\
6\end{array}$ & $\begin{array}{r}33 \\
7 \\
40\end{array}$ & $\begin{array}{c}13(39) \\
7(100) \\
20(50)^{\star}\end{array}$ \\
\hline
\end{tabular}

$\star p<0.01$ (Fisher's exact test)

$\mathrm{MR+}=$ any abnormality present on MRI; Faz- = criteria of Fazekas et al ${ }^{46}$ not satisfied; Faz+ = criteria of Fazekas et al ${ }^{46}$ satisfied.

There was no significant effect of magnet field strength on the number of lesions detected.

\section{Discussion}

MRI was used in the present study to ascertain the frequency of clinically silent abnormalities thought likely to be due to multiple sclerosis and thereby to consolidate and extend the concordance rates that had already been calculated from clinical criteria alone.

One limitation is that we were only able to obtain MRI on $9 / 11(82 \%)$ clinically affected and $55 / 94(59 \%)$ of the clinically unaffected co-twins of index cases included in the clinical study. ${ }^{2}$ Twins who were scanned had demographic characteristics similar to the entire cohort, however, and it seems reasonable to regard them as representative of the larger group. In particular, it should be emphasised that the $\mathbf{5 5}$ clinically unaffected co-twins who participated in the MRI study had all been screened by a clinician and did not have neurological symptoms or signs; this cohort was therefore unlikely to be biased through willingness to undergo MRI as a result of personal anxiety about disease.

The MRI was diagnostically useful in the $8 / 9$ clinically affected twins of patients with multiple sclerosis who were examined. It displayed one or more lesions compatible with multiple sclerosis, however, in all nine, and in none did it reveal alternative diagnoses to account for the symptoms. In three, the diagnostic category of multiple sclerosis was made more certain after the MRI result was taken into account.

In evaluating the significance of abnormalities on MRI in the clinically unaffected twins, it is necessary to consider their age. Numerous surveys on healthy subjects aged over 60 have revealed a high frequency

Table 3 MRI findings in healthy co-twins

\begin{tabular}{|c|c|c|c|c|}
\hline & \multicolumn{2}{|c|}{ Monozygotic } & \multicolumn{2}{|c|}{ Dizygotic } \\
\hline & $n$ & $\begin{array}{l}\text { Multiple sclerosis criteria } \\
\text { satisfied }\end{array}$ & $n$ & $\begin{array}{l}\text { Multiple sclerosis criteria } \\
\text { satisfied }\end{array}$ \\
\hline $\begin{array}{l}\text { Alpérovich et al }{ }^{13} \\
\text { Sadovnick et al }{ }^{12} \\
\text { United Kingdom study } \\
\text { Total }\end{array}$ & $\begin{array}{l}13 \\
21 \\
15 \\
49\end{array}$ & $\begin{array}{l}3 \\
4 \\
2 \\
9(18 \cdot 4 \%)\end{array}$ & $\begin{array}{l}29 \\
11 \\
33 \\
73\end{array}$ & $\begin{array}{l}6 \\
1 \\
3 \\
10(13 \cdot 7 \%)\end{array}$ \\
\hline
\end{tabular}

(40-100\%) of multifocal abnormalities of white matter. ${ }^{37}{ }^{3841-46}$ Such MRI findings have been correlated pathologically with cerebral small vessel disease. ${ }^{39}{ }^{40}$ Because MRI is so often abnormal in this age group, the finding that all seven dizygotic twins aged over 60 had an abnormal MRI should be interpreted cautiously. Even criteria that are more specific for multiple sclerosis than simply the presence of an abnormality of white matter have been shown to be at their least specific among the elderly subjects. ${ }^{47}$ It is likely that most of the MRI abnormalities seen in these seven elderly dizygotic twins are due to incidental agerelated vascular disease, but the possibility that some are due to multiple sclerosis cannot be excluded. To achieve a reasonable degree of specificity for multiple sclerosis, however, it is wise to confine the analysis to younger adults (aged less than 60).

If it is assumed that all twins aged less than 60 with an abnormal scan actually have multiple sclerosis, the overall (clinical plus radiological) concordance rate would be $55 \%$ for monozygotic and $41 \%$ for dizygotic twins. If the stricter criteria of Fazekas et al ${ }^{46}$ are applied for MRI diagnosis, the overall concordance rates are $34 \%$ and $12 \%$ for monozygotic and dizygotic twins respectively.

Several previous studies have reported MRI findings in clinically unaffected twins of patients with multiple sclerosis. Kinnunen et $a l^{49}$ found no abnormalities on low field strength MRI in five monozygotic and six dizygotic clinically unaffected twins, McFarland et $a^{50}$ in 1/3 monozygotic and 0/1 dizygotic (MRI was also normal in the clinically affected member of the dizygotic pair) and Uitdehaag et $a l^{51}$ in 3/4 monozygotic and $0 / 3$ dizygotic. These are small numbers, and the last two studies recruited subjects by public appeal, which introduces an important ascertainment bias. The recent French ${ }^{12}$ and Canadian update ${ }^{11}$ studies provide MRI data on 42 and 32 clinically unaffected co-twins respectively. The first used the criteria of Paty and associates ${ }^{31}$ for the MRI diagnosis of multiple sclerosis, the second criteria of Fazekas et al. ${ }^{46}$ The MRI findings in these two studies are in agreement with our results (table 3) with less than $20 \%$ of asymptomatic subjects having scans suggestive of demyelination; neither were there significant differences between monozygotic and dizygotic co-twins.

Even if the presence of any MRI abnormality is taken for the purposes of this study to indicate multiple sclerosis in clinically unaffected twins under the age of 60 , the concordance rate in monozygotic twins falls well short of the $100 \%$ needed to support a necessary genetic aetiology for multiple sclerosis; about one third are both clinically unaffected and have a completely normal MRI. It could be argued, somewhat improbably, that some of the remaining discordant monozygotic twins have purely spinal multiple sclerosis (a region not examined by MRI in this study), or that the disease has yet to express itself although the mean age of the cohort (42 years) is already beyond the age at which most 
patients first develop clinical symptoms of multiple sclerosis. What seems more likely is that these figures are in fact an overestimate of the true pathological frequency of the disease. The abnormalities shown with MRI were usually few in number and small in size (fig 2), and it is notable that minor abnormalities not fulfilling the criteria of Fazekas et $a l^{46}$ were only slightly more frequent in both categories of twins than in healthy singleton controls $($ monozygotic $=4 / 15, \quad 27 \% ; \quad$ dizygotic $=$ $10 / 33,30 \%$; controls $=7 / 37,19 \%$; NS). It is also possible that such minor differences as exist could be due to being a twin per setwins are more liable than singletons to perinatal trauma and prematurity, which might conceivably produce non-specific MRI abnormalities.

The nature and frequency of the abnormalities in our 20-60 year old controls are similar to those reported in other series. ${ }^{36-45}$ Although definitive pathological correlation is not available, several lines of evidence favour a vascular process: (1) the lesions are predominantly punctate, and discretely placed in the deep cerebral or subcortical white matter, similar to the pattern in elderly controls where the lesions have been correlated with vascular disease, and unlike classical multiple sclerosis in which periventricular lesions predominate; (2) the lesions are more often seen in the presence of risk factors for cerebrovascular disease such as hypertension ${ }^{37} 384145$ or with a history of frequent classical migraine attacks ${ }^{36}$; (3) such lesions are seen in $20 \%$ or more of healthy adults aged less than 60 , and it is inherently unlikely that multiple sclerosis approaches anything close to this frequency in the general population. Given the frequency of abnormalities on MRI, it would seem wise to develop MRI criteria that are more specific for multiple sclerosis, even in this younger age group. Several criteria for diagnosis of multiple sclerosis by MRI have been devised. ${ }^{2631} 5246$ None is absolutely specific. The most thoroughly validated criteria are those of Fazekas et al, ${ }^{46}$ which in a study of 1500 consecutive cases had a $96 \%$ specificity and an $81 \%$ sensitivity for multiple sclerosis. ${ }^{47}$ Most of the false positive diagnoses were found in older patients suggesting that the specificity was nearer $99 \%$ in those under 60 years old. It is notable that none of 37 healthy controls in the present study had abnormalities that fulfilled the criteria of Fazekas et al. ${ }^{46}$ Although multiple sclerosis can undoubtedly be present without these criteria being met, their application will only exclude a few genuine cases and the use of less rigorous criteria will undoubtedly lead to significant overascertainment by including those with minor, non-specific, age-related vascular changes.

We therefore conclude that the true pathological concordance for multiple sclerosis in this twin series aged less than 60 is probably around $35 \%$ for monozygotic and $10 \%$ for dizygotic twins. The frequency of MRI abnormality is no greater in the clinically unaffected monozygotic than dizygotic twins, and MRI only increases the concordance rate in either group by about $10 \%$ over that obtained through clinical assessment alone. Whereas the higher overall concordance in monozygotic twins confirms a contribution of genetic factors to the aetiology of multiple sclerosis, the lack of clear clinical or MRI evidence for multiple sclerosis in about two thirds of monozygotic twins suggests that environmental factors are also relevant.

1 Bundey S. Uses and limitations of twin studies. $f$ Neurol 1991;238:360-4

2 Mumford CJ, Wood NW, Kellar-Wood H, et al. The British Isles survey of multiple sclerosis in twins. Neurology 1994;44:11-5.

3 Mackay RP, Myrianthopoulos NC. Multiple sclerosis in twins and their relatives. Arch Neurol 1966;15:449-62.

4 Bobowick AR, Kurtzke JF, Brody JA, et al. Twin study of multiple sclerosis: an epidemiological inquiry. Neurology 1978;28:978-87.

5 Williams A, Eldridge R, McFarland $\mathrm{H}$, et al. Multiple sclerosis in twins. Neurology 1980;30:1139-47.

6 Currier RD, Eldridge R. Possible risk factors in multiple sclerosis as found in a national twin study. Arch Neurol 1982;39:140-4

7 Heltberg A, Holm NV. Concordance in twins and recurrence in sibships in multiple sclerosis. Lancet 1982;i: rence 1068 .

8 Greenstein JI, McFarland HF, Jacobson S, et al. A fiveyear clinical and immunological follow-up study of twins
with multiple sclerosis. Ann Neurol 1984;16:140.

9 Ebers GC, Bulman DE, Sadovnick AD, et al. A population-based study of multiple sclerosis in twins. $N$ Eng $\mathcal{F}$ Med 1986;315:1638-42.

10 Kinnunen E, Koskenvuo M, Kaprio J, Aho K. Multiple sclerosis in a nationwide series of twins. Neurology 1987;37:1627-9

11 Sadovnick AD, Armstrong H, Rice GPA, et al. A population-based study of multiple sclerosis in twins: Update. Ann Neurol 1993;33:281-5

12 Alpérovich A, Hors J, Lyon-Caen O, et al. Multiple sclerosis in $\mathbf{5 4}$ twinships: concordance rate is independent of zygosity. Ann Neurol 1992;32:724-7.

13 McAlpine $\mathrm{D}$. The benign form of multiple sclerosis. A study based on 241 cases seen within three years of onset and followed up until the tenth year or more of the disand followed up until the tenth

14 Lehoczky T, Halasy-Lehoczky M. Forme "bénigne" de la sclérose en plaques. Presse Med 1963;71:2294-6.

15 Fog T, Hyllested K, Anderson SR. A case of benign multiple sclerosis, with autopsy. Acta Neurol Scand 1972; 48(suppl 51):369-70.

16 Georgi VW. Multiple Sklerose: Pathologisch-anatomische Befunde multipler Sklerose bei klinisch nicht diagnostizierten Krankheiten. Schweiz Med Wochenschr 1966;20: 605-7.

17 Mackay RP, Hirano A. Forms of benign multiple sclerosis. Report of two "clinically silent" cases discovered at autopsy. Arch Neurol 1967;17:588-600.

18 Morariu M, Klutzow WF. Subclinical multiple sclerosis. f Neurol 1976;213:71-6.

19 Gilbert JJ, Sadler M. Unsuspected multiple sclerosis. Arch Neurol 1983;40:533-6.

20 Phadke JG, Best PV. Atypical and clinically silent multiple sclerosis: a report of 12 cases discovered unexpectedly at sclerosis: a report of 12 cases discovered unexpectedly at

21 Engell T. A clinical patho-anatomical study of clinically silent multiple sclerosis. Acta Neurol Scand 1989;79: $428-30$.

$22 \mathrm{Xu} \mathrm{X-H,} \mathrm{McFarlin} \mathrm{DE.} \mathrm{Oligoclonal} \mathrm{bands} \mathrm{in} \mathrm{CSF:} \mathrm{twins}$ with MS. Neurology 1984;34:769-74.

23 Nuwer MR, Visscher BR, Packwood JW, Namerow NS. Evoked potential testing in relatives of multiple sclerosis patients. Ann Neurol 1985;18:30-4.

24 Young IR, Hall AS, Pallis CA, et al. Nuclear magnetic resonance of the brain in multiple sclerosis. Lancet 1981;ii: $1063-6$.

25 Ormerod IEC, Miller DH, McDonald WI, et al. The role of NMR imaging in the assessment of multiple sclerosis and isolated neurological lesions. A quantitative study. Brain 1987;110:1579-616.

26 Robertson WD, Li D, Mayo J, et al. Magnetic resonance imaging in the diagnosis of multiple sclerosis. 7 Neurol imaging in the diagno

27 Jacobs L, Kinkel PR, Kinkel WR. Silent brain lesions in patients with isolated idiopathic optic neuritis. Arch Neurol 1986;43:452-5.

28 Ormerod IEC, Bronstein A, Rudge P, et al. Magnetic resonance imaging in isolated lesions of the brainstem f Neurol Neurosurg Psychiatry 1986;49:737-43.

29 Ormerod IEC, McDonald WI, du Boulay EPGH, et al. Disseminated lesions at presentation in patients with optic neuritis. I Neurol Neurosurg Psychiatry 1986;49: 124-7

30 Miller DH, McDonald WI, Blumhardt LD, et al. Magnetic resonance imaging of isolated noncompressive spinal cord syndromes. Ann Neurol 1987;22:714-23. 
31 Paty DW, Oger JJF, Kastrukoff LF, et al. MRI in the diagnosis of MS: A prospective study with comparison of nosis of MS: A prospective study with comparison of clinical evaluation, olig

32 Lynch SG, Rose JW, Smoker W, Petajan JH. MRI in familial multiple sclerosis. Neurology 1990;40: 900-3

33 Tienari PJ, Salonen O, Wilkström J, et al. Familial multiple sclerosis: MRI findings in clinically affected and unaffected siblings. $\mathcal{F}$ Neurol Neurosurg Psychiatry 1992;55 883-6.

34 Miller DH, Ormerod IEC, Gibson A, et al. MR brain scanning in patients with vasculitis: differentiation from multiple sclerosis. Neuroradiology 1987;29:226-31.

35 Miller DH, Kendall BE, Barter $S$, et al. Maonetic resonance imaging in central nervous system sarcoidosis. Neurology 1988;38:378-83.

36 Ferbert A, Busse D, Thorn A. Microinfarction in classic migraine? A study with magnetic resonance imaging migraine? A study with magn

37 Awad IA, Spetzler RF, Hodak JA, et al. Incidental subcortical lesions identified on magnetic resonance imaging in the elderly. I. Correlation with age and cerebrovascula risk factors. Stroke 1986;17:1084-9.

38 Gerard G, Weisberg LA. MRI periventricular lesion in adults. Neurology 1986;36:998-1001.

39 Kirkpatrick JB, Hayman LA. White-matter lesions in MR imaging of clinically healthy brains of elderly subjects: possible pathologic basis. Neuroradiology 1987;162 509-11.

40 Braffman BH, Zimmerman RA, Trojanowski JQ et al. Brain MR: pathologic correlation with gross and histopathology. 1. Lacunar infarction and VirchowRobin spaces. Am $\mathcal{F}$ Roentgenol 1988;151:551-8.

41 Fazekas F, Niederkorn $K$, Schmidt $R$, et al. White matter signal abnormalities in normal individuals: correlation with carotid ultrasonography, cerebral blood flow measurements, and cerebrovascular risk factors. Stroke 1988;19:1285-8.

42 Brant-Zawadzki M, Fein G, Van Dyke C, et al. MR imaging of the aging brain: patchy white-matter lesions and dementia. Am f Neuroradiol 1985;6:675-82.

43 George AE, de Leon MJ, Kalnin A, et al. Leukoencephalopathy in normal and pathologic aging: 2. MRI of brain lucencies. Am $\mathcal{F}$ Neuroradiol 1986;7:567-70.

44 Hunt AL, Orrison WW, Yeo RA, et al. Clinical significance of MRI white matter lesions in the elderly. Neurology 1989;39:1470-4.

45 Fazekas F. Magnetic resonance signal abnormalities in asymptomatic individuals: their incidence and functional correlates. Eur Neurol 1989;29:164-8.

46 Fazekas F, Offenbacher H, Fuchs S, et al. Criteria for an increased specificity of MRI interpretation in elderly subjects with suspected multiple sclerosis. Neurology 1988;38:1822-5.

47 Offenbacher H, Fazekas F, Schmidt R, et al. Assessment of MRI criteria for a diagnosis of MS. Neurology 1993;43: 905-9.

48 Poser CM, Patey DW, Scheinberg L, et al. New diagnostic criteria for multiple sclerosis: guidelines for research protocols. Ann Neurol 1983;13:227-31.

49 Kinnunen E, Juntunen J, Ketonen L, et al. Genetic susceptibility to multiple sclerosis. A co-twin study of a nationwide series. Arch Neurol 1982;45:1108-11.

50 McFarland HF, Patronas NJ, McFarlin DE, et al. Studies of multiple sclerosis in twins, using nuclear magnetic resonance. Neurology 1985;35(suppl 1): 137.

51 Uitdehaag BMJ, Polman $\mathrm{CH}$, Valk J, et al. Magnetic resonance imaging studies in multiple sclerosis twins. I Neurol Neurosurg Psychiatry 1989;52:1417-9.

52 Cutler JR, Aminoff MJ, Brant-Zawadzki M. Evaluation of patients with multiple sclerosis by evoked potentials and magnetic resonance imaging: a comparative study. Ann Neurol 1986;20:645-8. 